\title{
IR ABSORPTION AND RAMAN SCATTERING OF WATER IN PHOSPHATE GLASSES: SIMLARITY AND DIFFERENCES
}

\section{TATIANA SMIRNOVA, VAVIK TER-NERSESYANTS, MARINA PESTRIKOVA} S. I. Vavilov State Optical Institute, Babushkin St., 36/1, St.-Petersburg, 193171 Russia

\begin{abstract}
The broad absorption band of water in phosphate glass near $3000 \mathrm{~cm}^{-1}$ contains several components belonging to different bonds of water ions. To determine the relation of these components, $\mathbb{R}$ absorption spectra in a broadened interval (up to $1400 \mathrm{~cm}^{-1}$ ) and Raman scattering spectra of the same samples were measured. All the measurements were collated with quantitative determinations of water content in the studied glasses that was done by means of nuclear microanalysis methods. A pilot decomposition of Raman band of water in vitreous $\mathrm{LiPO}_{3}$ was done using the same procedure as for the IR spectra. The calculated components show that the positions of the hydrogen-containing groups are similar in the Raman and the $\mathbb{R}$ spectra, however, their intensities being in inverse dependence. Furthermore, the Raman scattering bands are clearly different in the meta- and poly-phosphate regions. Of great importance is also the kind of the metal cation in the phosphate.
\end{abstract}

Water ions have various possibilities for incorporating into phosphate glassforming matrix for different $\mathrm{MeO} / \mathrm{P}_{2} \mathrm{O}_{5}$ ratios and different kinds of metal. These differences become clear in decomposition of broad absorption band of water near $3000 \mathrm{~cm}^{-1}$ $\left[\right.$ Polak $^{1}$, Efimov $\left.^{2}\right]$. This work proposes a version of decomposition of this band in a broadened interval $4500-1500 \mathrm{~cm}^{-1}$, i. e. up to the frequencies of the basic phosphate matrix. Specially recorded new absorption spectra and their decomposition coincide very well with earlier published data in $4000-2000 \mathrm{~cm}^{-1}$ [Smirnova ${ }^{3}$ ] because the decomposition in the interval of $2000-1500 \mathrm{~cm}^{-1}$ seems to be reliable (Table 1). The intensities of decomposition components were collated with quantitative determinations of water content in the studied glasses that was done by means of nuclear microanalysis methods [Ilchamov ${ }^{4}$ ]. For glasses containing the maximal amount of water and, accordingly, having the highest absorption near $3000 \mathrm{~cm}^{-1}$ the Raman scattering spectra were recorded - for $\mathrm{Ba}\left(\mathrm{PO}_{3}\right)_{2}$ (ger.) (about $0.45 \%$ wt. of water), $\mathrm{CaO} 2 \mathrm{P}_{2} \mathrm{O}_{5}$ (about 5.2 $\%$ wt. of water) and $\mathrm{LiPO}_{3}$ (about $0.6 \%$ wt. of water). The latter spectrum came out the most distinct because we did the pioneer decomposition of the Raman spectrum of water in the glass. The method of decomposition is the same for IR and Raman spectra. The calculated components show that the positions of the hydrogen-containing groups are 


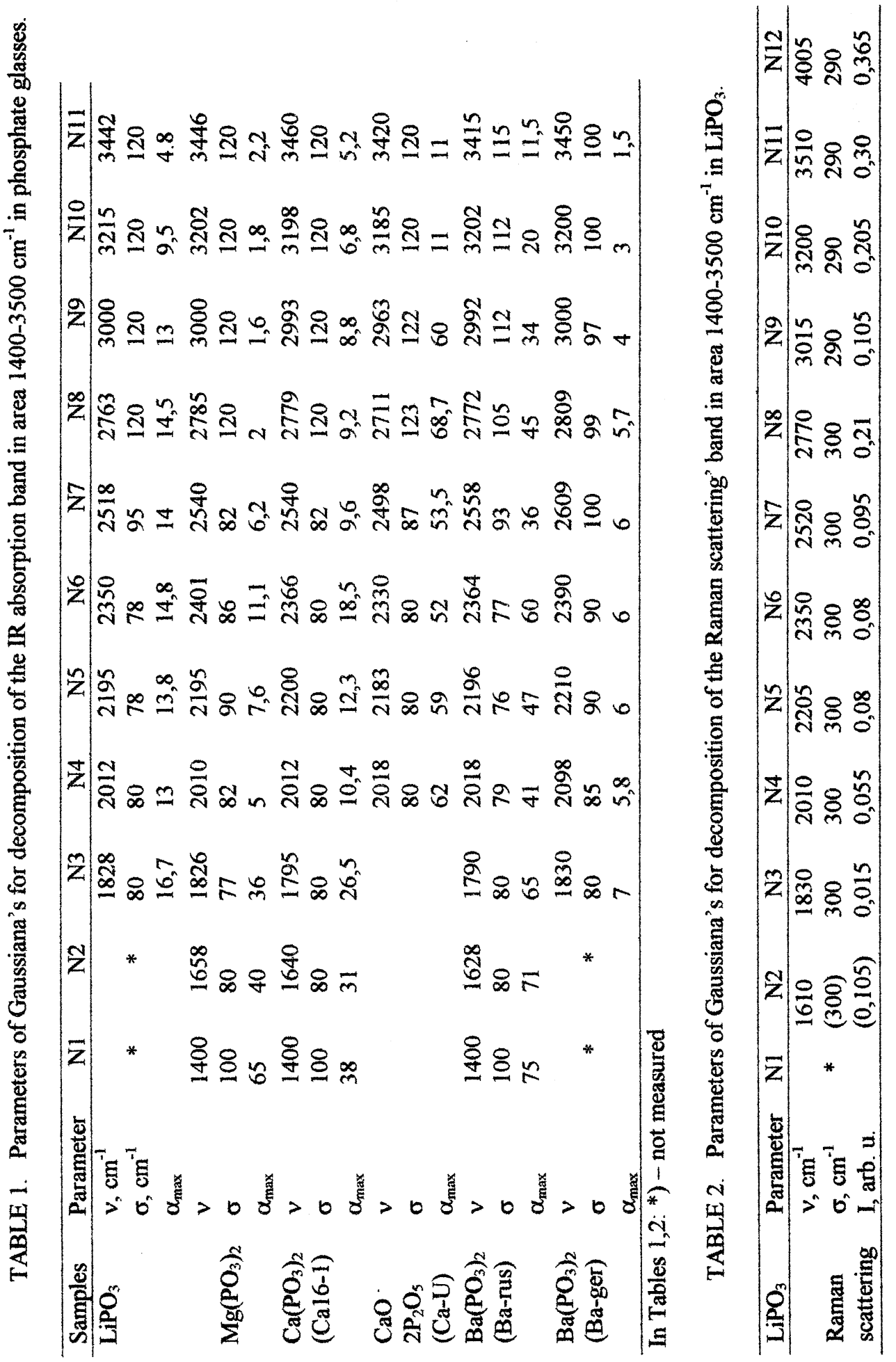




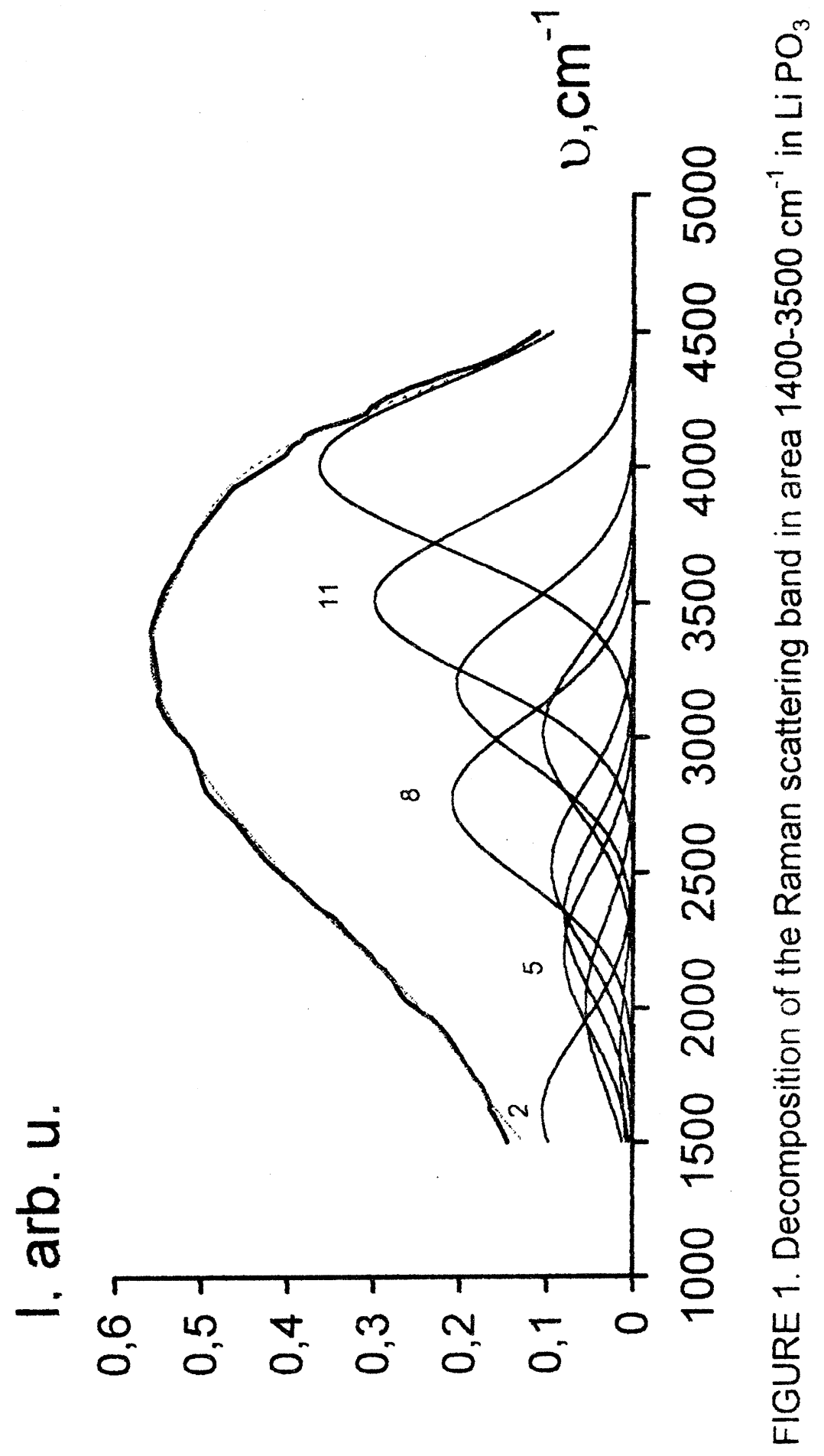


similar in Raman and IR spectra, and the intensities have an inverse dependence (Table 2). These results should be expected keeping in mind the alternative selection rule. Furthermore, the fitting of the decomposition spectrum made us add a new absorption band near $4005 \mathrm{~cm}^{-1}$, which is absent in the IR spectra. In Fig. 1 is shown the Raman spectrum of $\mathrm{LiPO}_{3}$ and its decomposition into components that are visible mostly in the original spectrum. The intensities of water-related bands in Raman scattering spectra are clearly different in meta- and poly-phosphate regions. The intensities of Raman scattering in $\mathrm{CaO} 2 \mathrm{P}_{2} \mathrm{O}_{5}$ and $\mathrm{Ba}\left(\mathrm{PO}_{3}\right)_{2}$ distinguish more than 10 times. This fact corresponds to water content in these glass. But the water-related bands in $\mathrm{CaO}_{2} \mathrm{P}_{2} \mathrm{O}_{5}$ have the intensities conaparable with those of main phosphate vibrations, and in $\mathrm{Ba}\left(\mathrm{PO}_{3}\right)_{2}$ they are negligible small. Of great importance is also the kind of the metal cation in the phosphate. For example, metaphosphates of $\mathrm{Li}$ (coordination number $\mathrm{CN}=4$ ) and $\mathrm{Ba}$ $(\mathrm{CN}=8)$ contain remarkably different symmetrical vibrations of water in the Raman spectra while the asymmetrical vibrations of water in these glasses (IR spectra) and water content are similar (Table 1).

The Raman scattering spectra were recorded by means of spectrophotometer Spex Ramalog 5 (Ioffe Physical Technical institute, St.-Petersburg, Russia). The authors gratefully appreciate $\mathrm{K}$. Kober for making the spectra.

\section{REFERENCES}

1. K. Polák, A. Bohun, and F. Fröhlich, Czech.J.Phys. B28, 576 (1978)

2. A.M. Efimov, T.G. Kostyreva, and G.A. Sycheva, J.Non-Cryst.Sol. 238, 124 (1998)

3. T. Smirnova, V. Ter-Nersesyants, M. Pestrikova, and V. Pogareva, Phos.Res.Bull. 10, 594 (1999)

4. R.A.Ilchamov, S.G. Lunter, V.E. Ter-Nersesyants, M.V. Pestrikova, and J.K. Fedorov, Sov. J.Phys. Chem. Glas. 18, 423 (1992) 